\title{
Different phenotypes of the NAT2 gene influences hydralazine antihypertensive response in patients with resistant hypertension
}

\begin{abstract}
Aim: Hydralazine, a vasodilator used in resistant hypertension $(\mathrm{RH})$ treatment is metabolized by an acetylation reaction mediated by $N$-acetyltransferase 2 , the activity of which depends on NAT2 polymorphisms. Our aim was to evaluate whether different acetylation phenotypes influenced the antihypertensive effect of hydralazine in patients with RH. Patients \& methods: DNA samples from 169 $\mathrm{RH}$ patients using hydralazine were genotyped by sequencing the NAT2 coding region, and acetylation phenotypes were defined. Results: Sixty-five patients (38.5\%) were intermediate, 60 (35.5\%) slow and 21 $(12.4 \%)$ fast acetylators. Twenty-three (13.6\%) patients were indeterminate. Upon association analysis, only slow acetylators had significant blood pressure reductions after hydralazine use, with mean 24-h systolic and diastolic blood pressure reductions of 9.2 and $5.5 \mathrm{mmHg}$. Four patients presented hydralazine adverse effects resulting in drug withdrawal, three of them were slow acetylators. Conclusion: The slow acetylation phenotype, determined by polymorphisms within NAT2, influenced both the antihypertensive and adverse effects of hydralazine in $\mathrm{RH}$.
\end{abstract}

Original submitted 31 May 2013; Revision submitted 7 October 2013

KEYWORDS: Brazilian population hydralazine NAT2 polymorphism resistant hypertension SNP

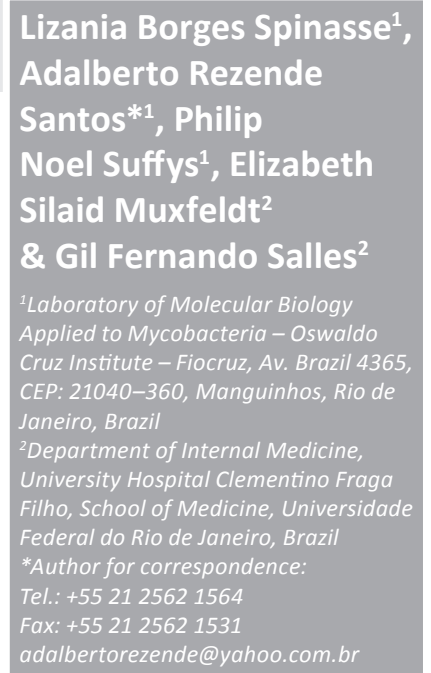

concurrent use of three or more antihypertensive drugs of different classes, including a diuretic, at their optimal doses [3,6]. Cases of pseudoresistance, which may result from poor compliance with treatment, inadequate antihypertensive medication, incorrect BP measurement or the white-coat effect, must be identified. Exaggerated white-coat effect (called white-coat RH) is present when the patient's $\mathrm{BP}$ is $<140 / 90 \mathrm{mmHg}$ at the doctor's office or hospital and $<135 / 85 \mathrm{mmHg}$ when measured out of office, preferentially by ambulatory BP monitoring $[3,6]$.

The objective of treating high BP is the prevention of hypertensive end-organ damage and reduction of cardiovascular morbidity and mortality. Control of ambulatory BP is the most important factor in improving cardiovascular prognosis in RH [7]. Its pharmacological treatment usually consists of the use of at least three antihypertensive drugs including a diuretic. Several drugs are commonly used as first-line combinations in $\mathrm{RH}$ treatment, including diuretics, $\beta$-blockers, angiotensin-converting enzyme inhibitor (ACEI) or angiotensin II receptor antagonists, and calcium channel blockers. As an add-on fourth antihypertensive drug, spironolactone, an aldosterone antagonist diuretic, is often recommended [8].

\section{Future Medicine part of}


Hydralazine is a direct-acting vasodilator that has been used for the treatment of hypertension since 1952. Although it has largely been replaced by newer antihypertensive drugs with more acceptable tolerability profiles, hydralazine is still widely used in many countries due its lower cost [9] and particularly in RH, as a fifth drug in antihypertensive regimens. Hydralazine acts by dilating resistance arterioles, thus reducing peripheral resistance. It is primarily metabolized in the liver, by an acetylation reaction, and also forms hydrazones (e.g., the pyruvic acid hydrazone and the acetone hydrazone), which may have some activity in reducing BP. The rate of the $N$-acetylation step has a trimodal distribution and is determined genetically. The acetylation status determines hydralazine systemic biovailability and, because response is determined to a significant extent by serum drug levels, it also determines the drug response [10]. Thus, the acetylation phenotype may influence interindividual variations in hydralazine effectiveness, as well as the incidence of adverse side effects. Indeed, three major genetically determined phenotypes are observed: fast, intermediate and slow acetylators. Hydralazineinduced systemic lupus erythematosus, the mostfeared side effect, has mainly been associated with the slow acetylator phenotype [11,12].

Table 1. Frequency of point mutations in the NAT2 gene among

169 Brazilian patients with resistant hypertension using hydralazine.

\begin{tabular}{|c|c|c|c|c|}
\hline $\begin{array}{l}\text { SNPS } \\
(n=15)\end{array}$ & $\begin{array}{l}\text { Alleles } \\
(n=338)\end{array}$ & $\begin{array}{l}\text { Frequency } \\
(\%)^{\dagger}\end{array}$ & Effect & $\begin{array}{l}\text { Amino acid } \\
\text { change }\end{array}$ \\
\hline $29 A$ & 01 & 0.30 & Missense & I10T \\
\hline $30 A^{\ddagger}$ & 05 & 1.48 & Synonymous & |11। \\
\hline $33 \mathrm{~A}$ & 11 & 3.25 & Synonymous & G12G \\
\hline $191 A^{\S}$ & 07 & 2.10 & Missense & R64Q \\
\hline $282 T^{\S}$ & 104 & 31.0 & Synonymous & Y94Y \\
\hline $341 C^{\S}$ & 124 & 36.6 & Missense & I114T \\
\hline $403 G$ & 05 & 1.48 & Missense & L135V \\
\hline $481 T^{\S}$ & 117 & 34.6 & Synonymous & L161L \\
\hline $590 A^{\S}$ & 65 & 19.2 & Missense & R197Q \\
\hline $609 \mathrm{~T}$ & 02 & 0.60 & Missense & E203B \\
\hline $766 G$ & 03 & 0.89 & Missense & K256E \\
\hline $803 G^{\S}$ & 144 & 42.6 & Missense & K268R \\
\hline $824 C^{\ddagger}$ & 02 & 0.60 & Missense & L274S \\
\hline $838 A$ & 02 & 0.60 & Missense & V280M \\
\hline $857 A^{\S}$ & 13 & 3.85 & Missense & G286E \\
\hline \multicolumn{5}{|c|}{$\begin{array}{l}{ }^{\dagger} \text { Frequency refers to } 338 \text { alleles. } \\
{ }^{\mp} \text { New SNPS. } \\
{ }^{5} \text { Most common SNPs in the world. }\end{array}$} \\
\hline
\end{tabular}

The enzyme arylamine $N$-acetyltransferase 2 , coded by the NAT2 gene, is involved in the human physiological response to a wide range of xenobiotic compounds, including many clinically useful drugs (e.g., hydralazine) and a variety of exogenous chemicals present in the diet and environment. NAT2 is a highly polymorphic gene and the presence of several SNPs in its coding region can alter its enzymatic activity [13]. Gene mapping studies in humans have demonstrated that NAT2 is an intronless gene located between 170 and $360 \mathrm{~kb}$ at chromosome $8 \mathrm{p} 22$, adjacent to clusters of $\mathrm{CpG}$ island, and presents a coding region of 873 pb that encodes a 290 -amino acid protein [14]. To date, the reference $N A T 2 * 4$ allele and 65 other allele variants, combinations of up to four SNPs within the coding region, have been identified and classified in human populations [101]. A total of 40 SNPs have been identified in the NAT2 coding region, including several rare SNPs [15].

Therefore, the aim of this study was to evaluate whether different acetylating phenotypes predicted by NAT2 genotypes influence the antihypertensive effect of hydralazine in patients with RH.

\section{Patients \& methods Selection of patients \& sample handling}

In a case-control epidemiologic study model, 169 consanguineously unrelated (defined by personal history), resistant hypertensive patients using hydralazine from the outpatient hypertension clinic of Clementino Fraga Filho University Hospital were enrolled in this study and stratified in subgroups according to the therapeutic outcomes concerning BP control. All patients had clinical, laboratory and ambulatory BP monitoring (ABPM) data collected at baseline and during follow-up. In total, 61 patients were not using hydralazine at baseline and hence had a before and after hydralazine ABPM. Patients with secondary causes of hypertension were excluded, except sleep apnea. Routinely, primary hyperaldosteronism was defined as a serum aldosterone:renin ratio of $>30$, renal artery stenosis by duplex scan or renal scintigraphy, and Cushing syndrome by morning serum cortisol $>50 \mathrm{nmol} / \mathrm{l}$ after a midnight 1-mg dexamethasone suppression. Other secondary causes (pheochromocytoma or thyroid diseases) were investigated whenever there were any clinical signs and/or symptoms. Sleep apnea was not excluded because of its very 
high prevalence in patients with $\mathrm{RH}$ (nearly $80 \%)$. This study was approved by the Ethical Committee of Oswaldo Cruz Foundation and written informed consent was obtained from all of the enrolled patients.

A 5-ml sample of venous blood was collected from each patient and stored at $-20^{\circ} \mathrm{C}$. Genomic DNA was isolated from $200 \mu$ of frozen whole blood using the QIAamp ${ }^{\circledR}$ DNA Blood Mini Kit (Qiagen Inc., USA), according to the manufacturer's specifications. After extraction, DNA samples were stored at $-20^{\circ} \mathrm{C}$.

\section{NAT2 genotyping}

Genotyping of the NAT2 coding region was achieved by PCR and sequencing was performed using ABI PRISM Big Dye Terminator v.3.1 kit (PE Applied Biosystems, CA, USA) according to the manufacturer's recommendations on an ABI PRISM 3730 DNA Analyser (PE Applied Biosystems), as previously described [16]. Briefly, an 1093-bp DNA fragment comprising the entire NAT2 coding region was amplified by PCR and sequenced on both DNA strands using a set of primers for amplification (NAT2EF 5-TTAGTCACACGAGGAAATCAAA-3 and NAT2ER 5-AAATGCTGACATTTTTATGGATGA-3) and an additional internal set (NAT2 IF 5-ACCATTGACGGCAGGAATTA-3 and NAT2 IR 5-TGGTCCAGGTACCAGATTCC-3), designed with Primer3 software (Broad Institute, MA, USA) [102].

\section{Computational analysis}

After alignment with the reference sequence AY331807 (GenBank; National Center for Biotechnology Information, MD, USA) [103], sequence data of each sample were analyzed for SNPs identification through use of SeqScape v.2.6 software (PE Applied Biosystem) [104].

\section{Haplotype reconstruction}

To determine the haplotype pair of each patient and to define the acetylation status, haplotype reconstruction was performed using the program PHASE v.2.1.1 (University of Chicago, IL, USA) in default model for recombination rare variation $[17,18]$. Eight independent runs with 1000 interactions, 500 burn-in interactions and a thinning interval of one were performed. The run that showed the maximum consistency across eight runs was chosen. Additionally, the results that applied the PHASE algorithm repeatedly with default and varying values of number of interaction, burn-in interactions and the thinning interval was pursued.
Table 2. Genotype characterization of NAT2 gene and determination of acetylation status in 169 Brazilian patients with resistant hypertension using hydralazine.

\begin{tabular}{|c|c|c|}
\hline Cluster designation & Absolute number & Proportion (\%) \\
\hline$* 5 / * 5$ & 24 & 14.2 \\
\hline${ }^{* 5 / * 6}$ & 22 & 13.0 \\
\hline$* 5 / * 7^{\dagger}$ & 02 & 1.18 \\
\hline$* 5 / * 14^{+}$ & 03 & 1.78 \\
\hline${ }^{*} 6 /{ }^{*} 6^{+}$ & 03 & 1.78 \\
\hline$* 6 / * 14^{+}$ & 02 & 1.18 \\
\hline$* 7 / * 6^{+}$ & 04 & 2.38 \\
\hline Total slow acetylation & 60 & 35.5 \\
\hline$*_{4} / * 4$ & 13 & 7.70 \\
\hline$* 4 / * 12^{+}$ & 05 & 2.95 \\
\hline$* 4 / * 13^{+}$ & 01 & 0.59 \\
\hline$* 12 / * 12^{+}$ & 01 & 0.59 \\
\hline$* 13 /{ }^{*} 13^{+}$ & 01 & 0.59 \\
\hline Total fast acetylation & 21 & 12.4 \\
\hline$* 4 / * 5$ & 21 & 12.4 \\
\hline$* 4 / * 6$ & 14 & 8.30 \\
\hline$* 4 / * 7^{\dagger}$ & 05 & 2.95 \\
\hline$* 4 / * 14^{+}$ & 02 & 1.18 \\
\hline$* 5 / * 12^{+}$ & 08 & 4.70 \\
\hline$* 5 / * 13^{+}$ & 08 & 4.70 \\
\hline$* 6 / * 12^{+}$ & 03 & 1.78 \\
\hline$* 6 / * 13^{+}$ & 04 & 2.38 \\
\hline Total intermediate acetylation & 65 & 38.4 \\
\hline Indeterminate acetylation & 23 & 13.6 \\
\hline Total & 169 & 100 \\
\hline
\end{tabular}

All the runs showed consistency across the eight runs chosen.

\section{Statistical analysis}

Statistical analysis included nonparametric Kruskal-Wallis and $\chi^{2}$ tests for comparisons among different acetylating subgroups, and Wilcoxon signed rank test and McNemar's test for comparisons of BPs before and after hydralazine use. All analyses were adjusted for multiple comparisons by Bonferroni's correction. Since for each independent variable three comparisons were performed (the three subgroups slow, rapid and indeterminate acetylator status were compared with the reference intermediate acetylator subgroup), p-values were considered significant if $<0.017$ (i.e., 0.05 divided by 3 ). Expected genotype frequencies were calculated 
RESEARCH ARTICLE Spinasse, Santos, Suffys, Muxfeldt \& Salles

Table 3. Baseline characteristics of all 169 resistant hypertension patients who used hydralazine during follow-up, divided according to NAT2 acetylation status.

\begin{tabular}{|c|c|c|c|c|c|}
\hline Characteristics & $\begin{array}{l}\text { All patients } \\
(n=169)\end{array}$ & $\begin{array}{l}\text { Intermediate } \\
\text { acetylator } \\
(n=65)\end{array}$ & $\begin{array}{l}\text { Slow } \\
\text { acetylator } \\
(n=60)\end{array}$ & $\begin{array}{l}\text { Rapid acetylator } \\
(n=21)\end{array}$ & $\begin{array}{l}\text { Indeterminate } \\
\text { acetylator } \\
(n=23)\end{array}$ \\
\hline Male (\%) & 27.8 & 30.8 & 23.3 & 14.3 & 43.5 \\
\hline Age (years) & $64.4(10.4)$ & $64.9(9.8)$ & $64.8(10.4)$ & $61.7(9.1)$ & $64.9(12.9)$ \\
\hline White ethnicity (\%) & 51.2 & 51.6 & 51.7 & 52.4 & 47.8 \\
\hline BMI $\left(\mathrm{kg} / \mathrm{m}^{2}\right)$ & $31.1(5.8)$ & $30.7(5.2)$ & $31.5(6.4)$ & $31.4(6.7)$ & $31.1(5.4)$ \\
\hline Waist circumference $(\mathrm{cm})$ & $101(12)$ & $100(11)$ & $101(11)$ & $103(13)$ & $101(15)$ \\
\hline Physical inactivity (\%) & 66.9 & 64.6 & 66.7 & 57.1 & 82.6 \\
\hline Diabetes (\%) & 40.2 & 32.3 & 46.7 & 57.1 & 30.4 \\
\hline Current smoker (\%) & 12.4 & 13.8 & 13.3 & 4.8 & 13.0 \\
\hline Dyslipidemia (\%) & 70.1 & 57.8 & 74.6 & $90.5^{*}$ & 73.9 \\
\hline \multicolumn{6}{|l|}{ Clinical target organ damage } \\
\hline Coronary heart disease (\%) & 20.1 & 21.5 & 25.0 & 9.5 & 13.0 \\
\hline Cerebrovascular disease (\%) & 16.2 & 12.3 & 11.7 & $36.8^{*}$ & 21.7 \\
\hline Peripheral arterial disease (\%) & 9.5 & 10.8 & 10.0 & 14.3 & 0 \\
\hline \multicolumn{6}{|l|}{ Subclinical target organ damage } \\
\hline Left ventricular hypertrophy (\%) & 73.0 & 72.6 & 67.2 & 71.4 & 90.9 \\
\hline Chronic kidney disease (\%) & 50.9 & 46.0 & 53.3 & 52.4 & 56.5 \\
\hline \multicolumn{6}{|l|}{ Antihypertensive treatment } \\
\hline Antihypertensive drugs in use ( $n$ ) & $4(3-5)$ & $4(3-5)$ & $4(3-5)$ & $4(3-5)$ & $4(3-5)$ \\
\hline ACE inhibitors/AR blockers (\%) & 93.5 & 92.3 & 93.3 & 90.5 & 100 \\
\hline$\beta$-blockers (\%) & 81.7 & 83.1 & 75.0 & 90.5 & 87.0 \\
\hline Calcium channel blockers (\%) & 57.4 & 56.9 & 60.0 & 52.4 & 56.5 \\
\hline Hydralazine (\%) & 63.9 & 67.7 & 58.3 & 57.1 & 69.6 \\
\hline Central $\alpha$ agonists (\%) & 17.2 & 18.5 & 16.7 & 19.0 & 13.0 \\
\hline \multicolumn{6}{|l|}{ Systolic BP at baseline $(\mathrm{mmHg})$} \\
\hline Clinic & $173(26)$ & $173(25)$ & $177(27)$ & $166(22)$ & $170(30)$ \\
\hline Ambulatory $24 \mathrm{~h}$ & $137(18)$ & $135(17)$ & $140(17)$ & $137(21)$ & $134(19)$ \\
\hline Ambulatory daytime & $139(17)$ & $137(18)$ & $143(17)$ & $136(23)$ & $140(19)$ \\
\hline Ambulatory night-time & $127(20)$ & $125(20)$ & $129(20)$ & $127(20)$ & $130(21)$ \\
\hline \multicolumn{6}{|l|}{ Diastolic BP at baseline $(\mathrm{mmHg})$} \\
\hline Clinic & $96(17)$ & $97(16)$ & $97(18)$ & $92(18)$ & $94(16)$ \\
\hline Ambulatory $24 \mathrm{~h}$ & $80(12)$ & $80(11)$ & $80(11)$ & $76(15)$ & $80(13)$ \\
\hline Ambulatory daytime & $82(13)$ & $82(12)$ & $83(12)$ & $78(16)$ & $82(14)$ \\
\hline Ambulatory night-time & $73(13)$ & $73(13)$ & $72(12)$ & $69(14)$ & $74(14)$ \\
\hline Nondipping pattern (\%) & 55.4 & 57.1 & 47.5 & 61.9 & 65.2 \\
\hline Uncontrolled ambulatory BP (\%) & 62.3 & 56.3 & 71.2 & 52.4 & 65.2 \\
\hline \multicolumn{6}{|l|}{ Laboratory variables } \\
\hline Fasting glycemia (mg/dl) & $123(57)$ & $122(61)$ & $123(54)$ & $123(43)$ & $127(66)$ \\
\hline
\end{tabular}


Table 3. Baseline characteristics of all 169 resistant hypertension patients who used hydralazine during follow-up, divided according to NAT2 acetylation status (cont.).

\begin{tabular}{|c|c|c|c|c|c|}
\hline Characteristics & $\begin{array}{l}\text { All patients } \\
(n=169)\end{array}$ & $\begin{array}{l}\text { Intermediate } \\
\text { acetylator } \\
(n=65)\end{array}$ & $\begin{array}{l}\text { Slow } \\
\text { acetylator } \\
(n=60)\end{array}$ & $\begin{array}{l}\text { Rapid acetylator } \\
(n=21)\end{array}$ & $\begin{array}{l}\text { Indeterminate } \\
\text { acetylator } \\
(n=23)\end{array}$ \\
\hline \multicolumn{6}{|c|}{ Laboratory variables (cont.) } \\
\hline Total cholesterol (mg/dl) & $208(46)$ & $208(46)$ & $208(46)$ & $204(44)$ & $212(51)$ \\
\hline HDL-cholesterol (mg/dl) & $46(13)$ & $47(15)$ & $47(12)$ & $44(10)$ & $46(15)$ \\
\hline Triglycerides (mg/dl) & $162(88)$ & $164(83)$ & $150(93)$ & $169(81)$ & $181(92)$ \\
\hline Serum creatinine (mg/dl) & $0.9(0.8-1.2)$ & $0.9(0.7-1.2)$ & $0.9(0.8-1.1)$ & $1.0(0.8-1.2)$ & $1.0(0.7-1.3)$ \\
\hline $\begin{array}{l}\text { Glomerular filtration rate } \\
\left(\mathrm{ml} / \mathrm{min} / 1.73 \mathrm{~m}^{2}\right)\end{array}$ & $72(56-90)$ & $74(58-90)$ & $76(55-92)$ & $70(55-87)$ & $70(55-86)$ \\
\hline Albuminuria (mg/24 h) & $19(11-69)$ & $17(11-57)$ & $18(11-63)$ & $23(72-460)$ & $25(12-80)$ \\
\hline
\end{tabular}

from respective single allele frequencies according to the Hardy-Weinberg equation. The observed and expected gene frequencies were compared using a $\chi^{2}$ test for Hardy-Weinberg equilibrium. All statistics were carried out using SPSS statistical package version 19.0.

\section{Results}

Genetic variability of the NAT2 gene in the studied population

Sequence analysis of the NAT2 from 169 patients enrolled in this study revealed the presence of 15 different SNPs, 13 already described and registered in the official site of NAT2 nomenclature [101] and two new SNPs located at positions 30 and $824(30 \mathrm{~T}>\mathrm{A}$ and $824 \mathrm{~T}>\mathrm{C})$. The SNP at position 30 is synonymous, while the $824 \mathrm{~T}>\mathrm{C}$ is a nonsynonymous one leading to an amino acid change from the leucine residue to serine at codon 274 (Leu274Ser). Seven of the identified SNPs represent the most frequently found NAT2 SNPs among different populations. TABLE 1 shows the frequency of each SNP variant, the effect on protein sequence and the amino acid changes.

\section{- Haplotype reconstruction, allele characterization \& phenotype determination}

After haplotype pair reconstruction, 30 NAT2 alleles were characterized, from which 11 were new. After genotype determination, patients were classified as intermediate, slow and fast acetylators. TAвLE 2 shows the selected haplotypes, allele frequencies, as well the acetylation phenotypes. From a total of 169 patients, 65 (38.5\%; 95\% CI: 30.2-49.0\%) were classified as intermediate, 60 (35.5\%; 95\% CI: $27.6-45.7 \%$ ) as slow and 21
(12.4\%; 95\% CI: 8.1-19.0\%) as fast acetylators. From the remaining 23 patients $(13.6 \%$; $95 \% \mathrm{CI}$ : 9.0-20.5\%) no characterization of the acetylation phenotype was achieved.

\section{Association between NAT2 acetylating phenotypes \& BP reduction} Among the 169 patients enrolled in this study, baseline clinical, laboratory and BPs were identical among the subgroups, except that rapid acetylators had a higher prevalence of dyslipidemia and of cerebrovascular disease than the other subgroups (TAвцE 3). Sixty-one patients were not using hydralazine at baseline and hence had a before and after hydralazine ABPM. The median dose of hydralazine was $150 \mathrm{mg} / \mathrm{day}$ (range: 50-300 mg/ day). Table 4 shows clinic and ambulatory BP changes after hydralazine treatment. Significant $\mathrm{BP}$ reductions were observed only in the slow acetylation subgroup. Mean 24-h systolic and diastolic BP reductions were $9.2 \mathrm{mmHg}$ (95\% CI: 2.4-15.9 $\mathrm{mmHg}$ ) and $5.5 \mathrm{mmHg}(95 \% \mathrm{CI}$ : 1.3-9.8 mmHg), respectively; whereas mean clinic BP reductions were $18.6 \mathrm{mmHg}(95 \% \mathrm{CI}$ : $2.5-34.7 \mathrm{mmHg})$ and $8.8 \mathrm{mmHg}(95 \% \mathrm{CI}$ : $0.6-17.1 \mathrm{mmHg}$ ), respectively. In slow acetylators, hydralazine equally reduced both daytime and night-time BPs. Figures 1 \& 2 show clinic and ambulatory BP changes after hydralazine treatment. Four patients presented hydralazine adverse effects resulting in drug withdrawal, three of them were slow acetylators (one lupus-like syndrome).

\section{Discussion}

Currently, the influence of genetic variations on interindividual differences in pharmacological or toxicological response to drugs is 
well established. Pharmacogenetics/genomics are fields of growing importance in the postgenome era raising the possibility of customized therapy for different individuals. Pharmacogenetic studies of arylamine $N$-acetyltransferase genes (NAT1 and NAT2) were pioneering and variation in NAT activity was one of the earliest pharmacogenetic traits to be recognized [19]. Genetic polymorphisms within the NAT2 locus, giving rise to either 'slow' or 'fast' acetylation phenotypes, are associated with susceptibility to several diseases, such as different types of cancer and psoriasis $[20,21]$, and, in parallel, are also involved with response to environmental toxins and differences in therapeutic outcomes upon treatment with NAT2-metabolized drugs (e.g., dapsone, isoniazid and hydralazine). Genotype and phenotype correlation is well defined and the precise functional effects of most SNPs on acetylation are being characterized. The four common SNPs conferring an amino acid change to produce slow acetylating phenotypes are rs1801279 (191G>A; Arg64Gln) in NAT2*14, rs1801280 (341T>C; Ile114Thr) in NAT2*5, $N A T 2{ }^{*} 14 C$ and $N A T 2{ }^{*} 14 F, \quad$ rs 17799930 (590G>A; Arg197Gln) in NAT2*6, NAT2*5E and $N A T 2 * 14 D$, and rs1799931 $(857 \mathrm{G}>\mathrm{A}$; Gly286Glu) in NAT2*7. However, there are significant differences between interethnic populations in NAT2 allele distribution and frequency. For example, the slow acetylating allele NAT2*5, which is commonly found in Europeans and Africans, is extremely rare in Japanese, Koreans and Taiwanese. In our study we found 15 SNPs within the NAT2 coding region: rs72466456 $(29 \mathrm{C}>\mathrm{T}, 30 \mathrm{~T}>\mathrm{A}$ and $33 \mathrm{C}>\mathrm{A})$; rs1801279 $(191 \mathrm{G}>\mathrm{A}) ; \mathrm{rs} 1041983(282 \mathrm{C}>\mathrm{T}) ; \mathrm{rs} 1801280$ (341T>C and 403C>G); rs1799929 (481C>T);

\section{Table 4. Blood pressures in 61 resistant hypertensive patients who initiated hydralazine during follow-up,} divided according to NAT2 acetylation status.

\begin{tabular}{|c|c|c|c|c|c|}
\hline BP & $\begin{array}{l}\text { Hydralazine } \\
\text { use }\end{array}$ & $\begin{array}{l}\text { Intermediate } \\
\text { acetylator }(n=21)\end{array}$ & $\begin{array}{l}\text { Slow acetylator } \\
(n=24)\end{array}$ & $\begin{array}{l}\text { Rapid acetylator } \\
(n=9)\end{array}$ & $\begin{array}{l}\text { Indeterminate } \\
\text { acetylator }(n=7)\end{array}$ \\
\hline \multicolumn{6}{|l|}{ Systolic BP $(\mathrm{mmHg})$} \\
\hline \multirow[t]{2}{*}{ Clinic } & Before & $176(28)$ & $178(33)$ & $174(34)$ & $174(35)$ \\
\hline & After & $165(23)$ & $163(25)^{*}$ & $168(34)$ & $159(22)$ \\
\hline \multirow[t]{2}{*}{ Ambulatory $24 \mathrm{~h}$} & Before & $138(15)$ & $143(15)$ & $142(13)$ & $144(13)$ \\
\hline & After & $144(18)$ & $134(17)^{*}$ & $139(18)$ & $152(23)$ \\
\hline \multirow[t]{2}{*}{ Ambulatory daytime } & Before & $140(16)$ & $146(14)$ & $144(14)$ & $146(13)$ \\
\hline & After & $147(19)$ & $136(17)^{*}$ & $141(18)$ & $155(26)$ \\
\hline \multirow[t]{2}{*}{ Ambulatory night-time } & Before & $131(15)$ & $135(17)$ & $133(13)$ & $137(18)$ \\
\hline & After & $133(19)$ & $126(21)^{*}$ & $130(16)$ & $140(14)$ \\
\hline \multicolumn{6}{|l|}{ Diastolic BP $(\mathrm{mmHg})$} \\
\hline \multirow[t]{2}{*}{ Clinic } & Before & $96(18)$ & $94(19)$ & $86(18)$ & $91(15)$ \\
\hline & After & $88(11)$ & $87(18)^{*}$ & $83(21)$ & $86(11)$ \\
\hline \multirow[t]{2}{*}{ Ambulatory $24 \mathrm{~h}$} & Before & $81(10)$ & $80(9)$ & $74(12)$ & $83(10)$ \\
\hline & After & $83(14)$ & $75(11)^{\star *}$ & $75(12)$ & $87(12)$ \\
\hline \multirow[t]{2}{*}{ Ambulatory daytime } & Before & $83(11)$ & $82(10)$ & $77(12)$ & $85(10)$ \\
\hline & After & $86(14)$ & $76(11) \star *$ & $77(12)$ & $88(14)$ \\
\hline \multirow[t]{2}{*}{ Ambulatory night-time } & Before & $75(10)$ & $74(9)$ & $67(14)$ & $79(14)$ \\
\hline & After & $76(16)$ & $69(11)^{*}$ & $68(11)$ & $80(10)$ \\
\hline \multirow[t]{2}{*}{ Nondipping pattern (\%) } & Before & 61.9 & 70.8 & 66.7 & 71.4 \\
\hline & After & 47.6 & 54.2 & 66.7 & 57.1 \\
\hline \multirow[t]{2}{*}{ Uncontrolled daytime BP (\%) } & Before & 61.9 & 79.2 & 77.8 & 85.7 \\
\hline & After & 76.2 & $37.5^{\star *}$ & 66.7 & 85.7 \\
\hline
\end{tabular}


rs1799930 (590G>A, 609G $>\mathrm{T}$ and $766 \mathrm{~A}>\mathrm{G})$; rs1208 (803A $>\mathrm{G}, 824 \mathrm{~T}>\mathrm{C}$ and $838 \mathrm{G}>\mathrm{A})$; rs1799931 (857G>A), of which seven are the most frequent SNPs in the world and two, at positions 30T>A (silent) and $824 \mathrm{~T}>\mathrm{C}$ (nonsynonymous L274S), are new SNPs. After haplotype characterization, the most frequent allele was the $N A T 2 * 5 B(28 \%)$, which carries the nonsynonymous mutation rs1801280 341T>C resulting in one of the most altered isoforms of NAT2 in comparison with the other slow isoforms. The $N A T 2{ }^{*} 6 A$ allele, which carries the nonsynonymous mutation rs1799930 590G $>A$, was present in $16.3 \%$; while $N A T 2 * 7 B$, carrying the nonsynonymous mutation rs1799931 $857 \mathrm{G}>\mathrm{A}$, was present in $3.5 \%$ of the whole alleles found, mainly restricted to the Brazilian population from Rio de Janeiro. Regarding the alleles associated with fast acetylation, the NAT2* 4 allele, which is considered to be the wild-type and presenting no polymorphism, was found in $23 \%$ of our cohort. Finally, the distribution of the 'intermediate' phenotype, which results from heterozygous fast/slow alleles, was found in 65 patients (38.5\%).

Concerning the interethnic distribution of NAT2 SNPs, alleles and phenotypes, our findings are in accordance with a previous study from our group that compared NAT2 alleles found in another cohort from Rio de Janeiro with the ones found in Europeans, Asians, Amerindians and African populations, in which significant differences were observed [16]. Several studies suggest that these differences in phenotype patterns depend, at least in part, on lifestyle [22]. Recent genomic studies have provided growing evidence that cultural processes can have a profound impact on the human genome, triggering significant changes in allele frequencies in response to culturally modified environmental conditions [23]. In addition, the genetic diversity of NAT2 is structured in the human species, the major differences in allele frequencies exist between populations from different ethnic or geographic origins, but most genetic diversity occurs between individuals and this is the most important aspect, concerning both therapeutic and epidemiological applications [24,25].

Hydralazine is indicated for long-term therapy of essential hypertension, particularly in treatment-resistant patients, for short-term therapy of pregnancy-induced hypertension and eclampsia, and in the therapy of hypertensive crisis. The association between hydralazine response and acetylation status has already been previously reported [10], but, to our knowledge, our study

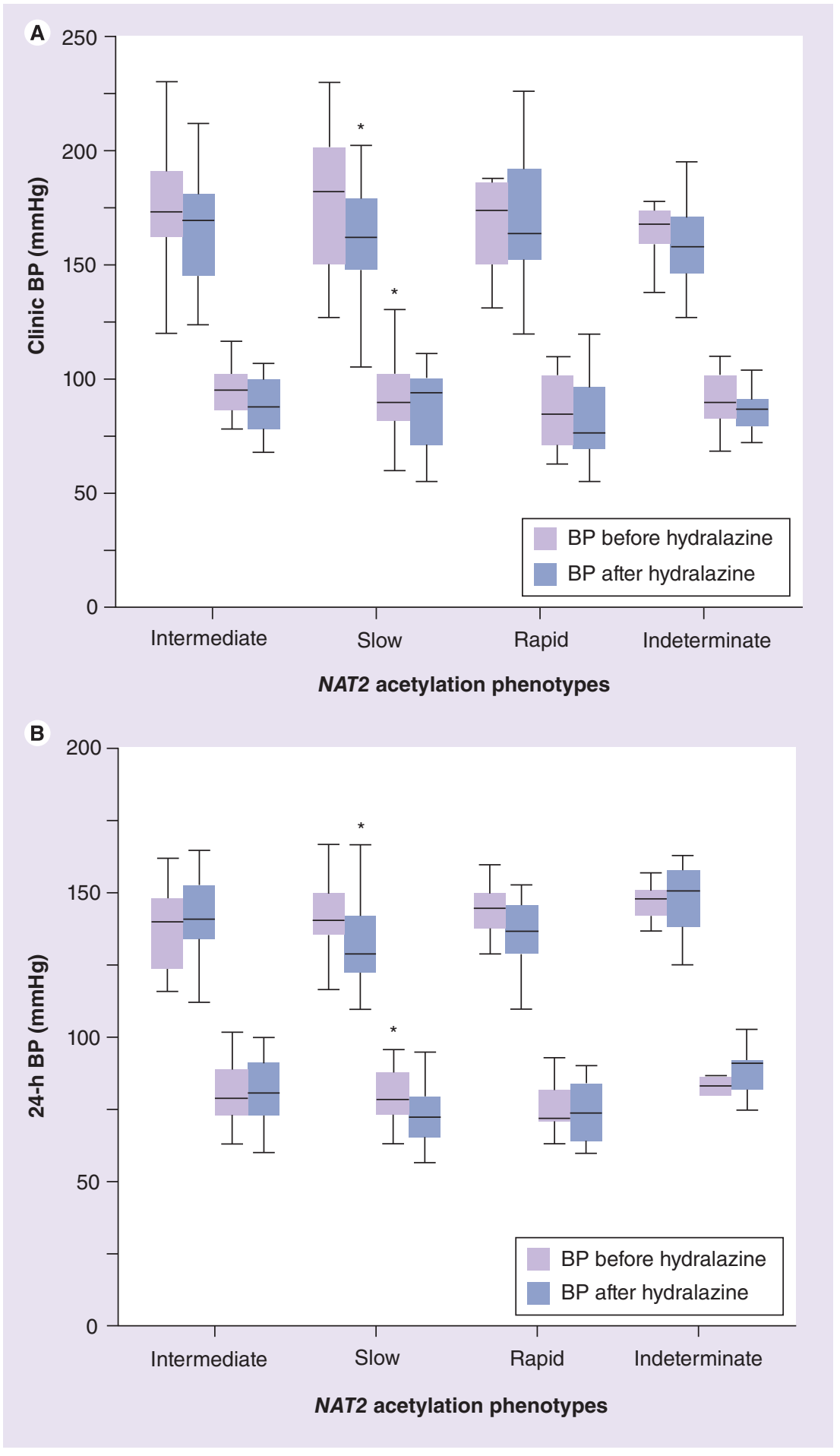

Figure 1. 24-h blood pressures before and after hydralazine use in resistant hypertensive patient groups. (A) Clinic and (B) ambulatory 24-h BPs before (purple boxes) and after (blue boxes) hydralazine use in resistant hypertensive patients grouped according to NAT2 acetylation phenotypes.

${ }^{*} p<0.05$.

BP: Blood pressure.

was the first to evaluate it in patients with $\mathrm{RH}$, an important subgroup of general hypertensives in whom hydralazine treatment is particularly indicated. 

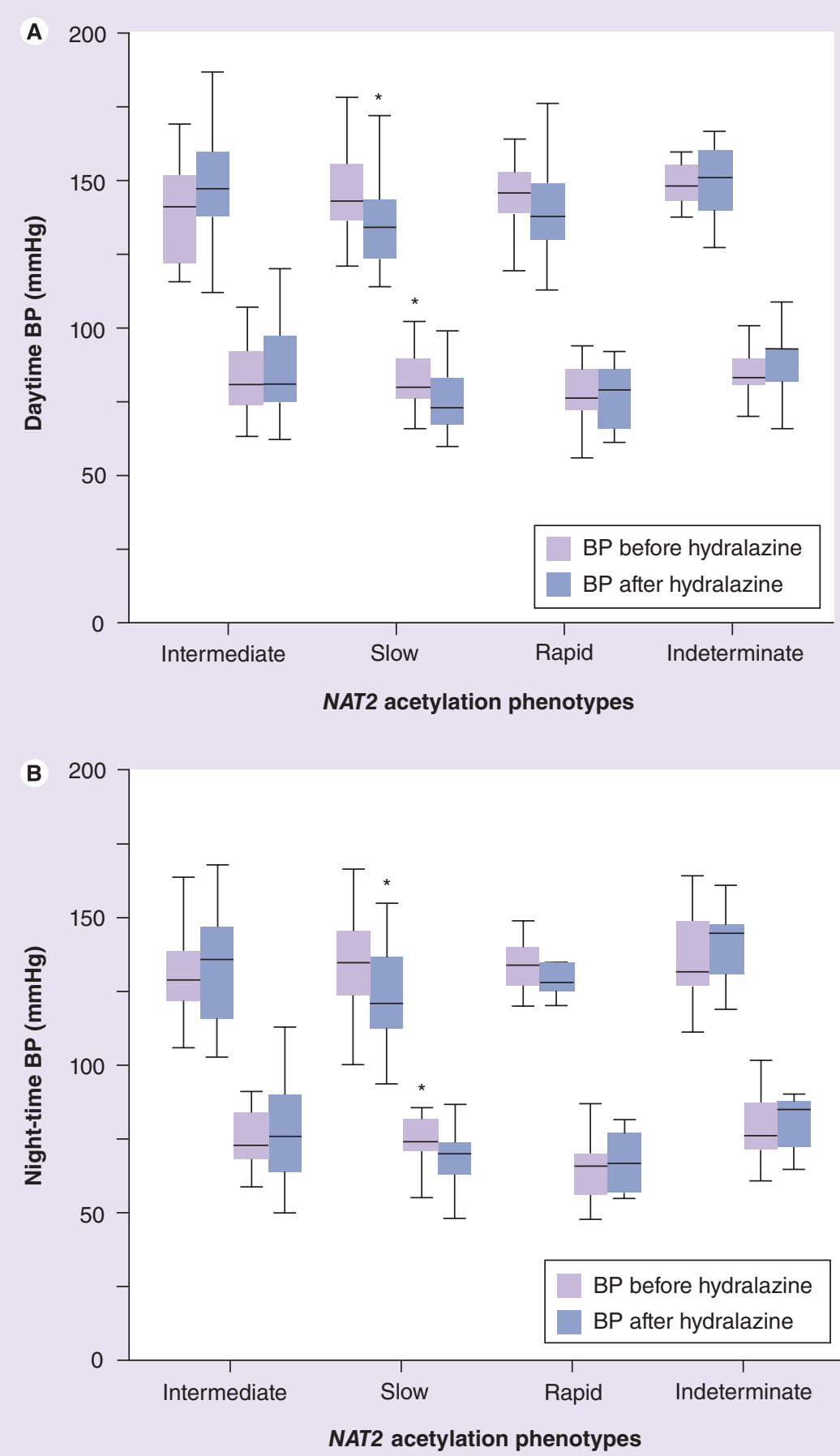

Figure 2. Ambulatory daytime and night-time blood pressures before and after hydralazine use in resistant hypertensive patient groups.

(A) Ambulatory daytime and (B) night-time blood pressures before (purple boxes) and after (blue boxes) hydralazine use in resistant hypertensive patients grouped according to NAT2 gene phenotypes of acetylation.

${ }^{*} \mathrm{p}<0.05$.

BP: Blood pressure. after 3 years of treatment in patients with the slow acetylating phenotype [26]. Drug-induced lupus erythematosus is defined as a lupus-like syndrome temporally related to continuous drug exposure, which resolves after discontinuation of the offending drug. There are currently no standard diagnostic criteria for drug-induced lupus erythematosus and the pathologic mechanisms are still unclear. Although hydralazine-induced lupus was thought originally to occur only in slow acetylators, it does occasionally occur in fast acetylators.

Our results suggest that NAT2 is the main genetic component responsible by the antihypertensive effect of hydralazine in RH. Only the slow acetylators had significant BP reductions after hydralazine use, although they also had higher incidence of adverse side effects. Patients with RH had a general poor antihypertensive response to drug treatment, moreover when an antihypertensive drug is added on a background of several other antihypertensive drugs already in use, as is the case for hydralazine that is usually used as a fourth or fifth drug in an antihypertensive regimen. That is why only the slow acetylators, inducing higher serum levels of the drug, presented a consistent antihypertensive effect.

Concerning the study limitations, we understand that the relatively small sample size (169 patients), although quite large for a study with resistant hypertensives, should be higher to increase the statistical power for a more comprehensive evaluation. Another issue is that no direct functional evaluation was performed, such as pharmacokinetic assays to detect hydralazine metabolites (e.g., the pyruvic acid and acetone hydrazones) in the urine of slow acetylators and comparison with different genetic profiles of acetylation. However, we used the BP response to hydralazine, evaluated by a confident method such as 24-h ambulatory BP monitoring [27], as the surrogate to detect different drug serum levels, as the antihypertensive effect of hydralazine is directly related to its serum levels [10]. Finally, although measurement of the acetylation phenotype is rather simple, it is not readily available to general practitioners. The safety of long-term hydralazine treatment is clearly related to the individual drug doses and acetylation status. In this study, NAT2 genotyping was performed by sequencing, overcoming the possible problems of misclassification of the acetylation status.

\section{Conclusion \& future perspective}

Genotyping interindividual variability at the NAT2 locus may not only help the identification 
of the best resistant hypertensive candidates to hydralazine treatment (the slow acetylators), but also the determination of the most suitable dosage for individual patients, possibly reducing adverse side effects, and the need for excessive outpatient visits and hospitalizations. Future studies should focus on larger samples of resistant hypertensive patients and also on cost-effective analysis of implementing treatment strategies of $\mathrm{RH}$ that takes into account pharmacogenetic evaluation of NAT2 polymorphisms.

\section{Acknowledgements}

The authors wish to thank the sequencing PDTIS-FIOCRUZ and Bioinformatics Platforms for their support.

\section{Financial \& competing interests disclosure}

The study was supported by research grants from the Conselho Nacional de Desenvolvimento Científico e Tecnológico
(CNPq) 400148/2011-0, the Fundação Carlos Chagas Filho de Amparo a Pesquisa do Estado do Rio de Janeiro (FAPERJ), the Oswaldo Cruz Institute (FIOCRUZ) and the Coordenação de Aperfeiçoamento de Pessoal de Nivel Superior (CAPES). The authors have no other relevant affiliations or financial involvement with any organization or entity with a financial interest in or financial conflict with the subject matter or materials discussed in the manuscript apart from those disclosed.

No writing assistance was utilized in the production of this manuscript.

\section{Ethical conduct of research}

The authors state that they have obtained appropriate institutional review board approval or have followed the principles outlined in the Declaration of Helsinki for all human or animal experimental investigations. In addition, for investigations involving human subjects, informed consent has been obtained from the participants involved.

\section{Executive summary}

- Hydralazine is an antihypertensive medication mainly used as an add-on fourth or fifth drug in a resistant hypertension treatment regimen. Its efficacy may depend on NAT2 gene polymorphisms that regulate metabolizing acetylation phenotypes; however, it has never been evaluated in resistant hypertensive patients.

- In 169 resistant hypertensive individuals, NAT2 genotyping showed that 38.4\% were intermediate, $35.5 \%$ were slow and $12.4 \%$ were fast acetylators, while $13.6 \%$ had an indeterminate acetylation status.

- On 24-h ambulatory blood pressure monitoring, only the slow acetylators had significant blood pressure reductions after hydralazine use, although they also had a higher incidence of adverse side effects.

- NAT2 genotyping may help to identify resistant hypertensive patients who would best benefit from hydralazine treatment.

\section{References}

Papers of special note have been highlighted as:

" of interest

" of considerable interest

1 Glavnik N, Petrovic D. M235T polymorphism of the angiotensinogen gene and insertion/ deletion polymorphism of the angiotensin-1 converting enzyme gene in essential arterial hypertension in Caucasians. Folia Biol. 53, 69-70 (2007).

2 Petrovic D. Association of the $-262 \mathrm{C} / \mathrm{T}$ polymorphism in the catalase gene promoter and the $\mathrm{C} 242 \mathrm{~T}$ polymorphism of the NADPH oxidase P22phox gene with essential arterial hypertension in patients with diabetes mellitus Type 2. Clin. Exp. Hypertens. doi:10.3109/106 41963.2013.783051 (2013) (Epub ahead of print).

3 Calhoun DA, Jones D, Textor $\mathrm{S}$ et al. Resistant hypertension: diagnosis, evaluation, and treatment: a scientific statement from the American heart association professional education committee of the council for high blood pressure research. Circulation 117, 510-526 (2008).

-" Unique comprehensive guideline on resistant hypertension management.
4 Persell SD. Prevalence of resistant hypertension in the United States, 2003-2008. Hypertension 57, 1076-1080 (2011).

5 Egan BM, Zhao Y, Axon N, Brzezinski WA, Ferdinand KC. Uncontrolled apparent treatment resistant hypertension in the United States, 1988 to 2008. Circulation 124 , 1046-1058 (2011).

6 Muxfeldt ES, de Souza F, Salles GF. Resistant hypertension: a practical clinical approach. J. Hum. Hypertens. 27(11), 657-662 (2013).

- Recent review on resistant hypertension.

7 Salles GF, Cardoso CRL, Muxfeldt ES. Prognostic influence of office and ambulatory blood pressure in resistent hypertension. Arch. Intern. Med. 168, 2340-2346 (2008).

- Prospective study showing the important prognostic value of ambulatory blood pressure control in resistant hypertension.

8 de Souza F, Muxfeldt ES, Fiszman R, Salles GF. Efficacy of spironolactone therapy in patients with true resistant hypertension. Hypertension 55, 147-152 (2010).

9 Kandler MR, Mah GT, Tejani AM, Stabler SN, Salzwedel DM. Hydralazine for essential hypertension. Cochrane Database Syst. Rev. 9 , CD004934 (2011).
"- Most recent systematic review on hydralazine use in hypertension.

10 Shepherd AM, McNay JL, Ludden TM, Lin MS, Musgrave GE. Plasma concentration and acetylator phenotype determine response to oral hydralazine. Hypertension 3, 580-585 (1981).

- Pioneering study showing the importance of acetylation status on hydralazine's antihypertensive effect in hypertensive patients.

11 Ladero JM. Influence of polymorphic $N$-acetyltransferases on non-malignant spontaneous disorders and on response to drugs. Curr. Drug Metab. 9, 532-537 (2008).

12 Agundez JA. Polymorphisms of human $N$-acetyltransferases and cancer acetylation polymorphisms. Cancer Epidemiol. Biomark. Prev. 9, 29-42 (2000).

13 Hein DW, Doll MA. Accuracy of various human NAT2 SNP genotyping panels to infer rapid, intermediate and slow acetylator phenotypes. Pharmacogenomics 13, 31-41 (2012).

" Most recent paper about NAT2 SNPs genotyping. 
14 Sim E, Walters K, Boukouvala S. Arylamine $N$-acetytransferases: from structure to function. Drug Metab. Rev. 40, 479-510 (2008).

15 Teixeira RL, Silva FP, Silveira AR et al. Sequence analysis of NAT2 gene in Brazilians: identification of undescribed single nucleotide polymorphisms and molecular modeling of the $\mathrm{N}$-acetyltransferase 2 protein structure. Mutat. Res. 683, 43-49 (2010).

16 Teixeira RL, Miranda AB, Pacheco AG et al. Genetic profile of the arylamine $\mathrm{N}$-acetytransferase 2 coding gene among individuals from two different regions of Brazil. Mutat. Res. 624, 31-40 (2007).

- Pioneering study showing genetic profile of NAT2 in regions of Brazil.

17 Li N, Stephens M. Modeling linkage disequilibrium and identifying recombination hotspots using nucleotide polymorphism data. Genetics 165, 2213-2233 (2003).

18 Stephens M, Donnelly P. A comparison of Bayesian methods for haplotype reconstruction. Am. J. Hum. Genet. 73, 1162-1169 (2003).

19 Walker K, Ginsberg G, Hattis D, Johns DO, Guyton KZ, Sonawane B. Genetic polymorphism in $N$-acetyltransferase (NAT): population distribution of NAT1 and NAT2 activity. J. Toxicol. Environ. Health B Crit. Rev. 12, 440-472 (2009).

20 Malik MA, Upadhyay R, Modi DR, Zargar SA, Mittal B. Association of NAT2 gene polymorphisms with susceptibility to esophageal and gastric cancers in the Kashmir valley. Arch. Med. Res. 40, 416-423 (2009).

21 Kozhekbaeva ZHM, Gra OA, Fadeev VS et al. Association of NAT2 polymorphisms with susceptibility to psoriasis in the Moscow population. Mol. Biol. 43, 62-76 (2009).

22 Sabbagh A, Darlu P, Crouau-Roy B, Poloni ES. Arylamine $N$-acetyltransferase 2 (NAT2) genetic diversity and traditional subsistence: a worldwide population survey. PLoS ONE 6(4), e18507 (2011).

"I- Recent paper about the genetic diversity of NAT2.

23 Pritchard JK, Pickrell JK, Coop G. The genetics of human adaptation: hard sweeps, soft sweeps, and polygenic adaptation. Curr. Biol. 20, R208-R215 (2010).

24 Magalon H, Patin E, Austerlitz F et al. Population genetic diversity of the NAT2 gene supports a role of acetylation in human adaptation to farming in central Asia. Eur. J. Hum. Genet. 16, 243-251 (2008).

25 McVicker G, Gordon D, Davis C, Green P. Widespread genomic signatures of natural selection in hominid evolution. PLoS Genet. 5, e1000471 (2009).

26 Yokogawa N, Vivino F. Hydralazine-induced autoimmune disease: comparison to idiopathic lupus and ANCA-positive vasculitis. Mod. Rheumatol. 19, 338-347 (2009).

27 Mancia G, Fagard R, Narkiewicz K et al. 2013 ESH/ESC guidelines for the management of arterial hypertension. The task force for the management of arterial hypertension of the European Society of Hypertension (ESH) and of the European Society of Cardiology (ESC). J. Hypertens. 31, 1281-1357 (2013).

\section{Websites}

101 Arylamine $N$-acetyltransferase Gene Nomenclature Committee. www.louisville.edu/medschool/ pharmacology/NAT.html

102 Primer3 Software. http://primer3.wi.mit.edu/

103 PubMed-GenBank. www.ncbi.nlm.nih.gov/GenBank

104 Applied Biosystems. www.appliedbioystems.com 